\title{
EVALUASI PENERAPAN KESELAMATAN DAN KESEHATAN KERJA (K3) PADA PEKERJAAN FINISHING BANGUNAN DI PROYEK PEMBANGUNAN PENYEDIAAN AIR BAKU SEMARANG BARAT
}

\author{
Andi Wiguna \\ Program Studi Teknik Sipil, Fakultas Teknik dan Informatika, Universitas PGRI Semarang \\ andiwix128@gmail.com \\ Putri Anggi Permata $S^{1}$, Donny Ariawan ${ }^{2}$ \\ 1-2 Program Studi Teknik Sipil, Fakultas Teknik dan Informatika, Universitas PGRI Semarang \\ ${ }^{1}$ putrianggipermata@upgris.ac.id, ${ }^{2}$ dyaria77@gmail.com
}

\begin{abstract}
Abstrak
Tujuan dilakukan penelitian ini adalah untuk mengetahui antecedents (input), transcription (proses), dan output (hasil) dari penerapan Keselamatan dan Kesehatan Kerja (K3) pada pekerjaan finishing bangunan di Proyek Pembangunan Penyedian Air Baku Semarang Barat. Metode evaluasi yang digunakan adalah Countenance Stake dengan 3 tahapan meliputi antecedents (input), transcription (proses), dan output. Subyek penelitian adalah pekerja di Proyek Pembangunan Penyediaan Air Baku Semarang Barat. Obyek penelitian adalah penerapan Keselamatan dan Kesehatan Kerja (K3). Sumber data yaitu pekerja di Proyek Pembangunan Penyediaan Air Baku Semarang Barat yang berjumlah 30 pekerja dan 3 safety officer. Data dikumpulkan melalui kuesioner, pengamatan, dan dokumentasi. Data dianalisis secara deskriptif. Hasil penelitian ini adalah : (1) antecedent (input) penerapan K3 pada pekerjaan finishing bangunan diproyek kostruksi ditinjau dari penetapan dasar hukum K3 dan pelaksanaan K3 sudah terlaksana sangat baik dilihat dari nilai rata-rata 28.33. (2) transcription (proses) penerapan $\mathrm{K} 3$ pada pekerjaan finishing bangunan diproyek konstruksi ditinjau dari perencanaa K3 dan Penerapan K3 sudah terlaksana dengan baik dilihat dari nilai rata-rata 24.67 yang sudah diterapkan dilapangan. (3) Output penerapan K3 pada pekerjaan finishing bangunan diproyek konstruksi ditinjau dari pemantauan $\mathrm{K} 3$ dan evaluasi kinerja K3 sudah terlaksana dengan baik dilihat dari nilai rata-rata 13.33.
\end{abstract}

Kata kunci: evaluasi, finishing bangunan, penerapan K3.

\begin{abstract}
The purpose of this research is to find out antecedents (inputs), transcriptions (process), and outputs (results) of the application of Occupational Safety and Health (K3) in building finishing work at the Baku Water Supply Development Project in West Semarang. The evaluation method used is the Countenance Stake with 3 stages including antecedents ((input),), transcription ((process), and output. The research subjects were workers at the Baku Water Supply Development Project in West Semarang. The object of research is the application of Occupational Safety and Health (K3). The data source is workers at the West Semarang Raw Water Supply Development Project which consists of 30 workers and 3 safety officers. Data is collected through questionnaires, observations, and documentation. The data is analyzed descriptively. The results of this study are: (1) antecedent (input) application of $\mathrm{K} 3$ on building finishing work construction project reviewed from the determination of the legal basis of $\mathrm{K} 3$ and the implementation of $\mathrm{K} 3 \mathrm{has}$ been carried out very well judging from the average value of 28.33 (2) transcription (process)application of $\mathrm{K} 3$ on building finishing work in construction projects reviewed from K3 planning and $\mathrm{K} 3$ implementation has been carried out well judging by the average value of 24.67 that has been applied in the field. (3) The output of K3 implementation on building finishing work in construction projects is reviewed from $\mathrm{K} 3$ monitoring and $\mathrm{K} 3$ performance evaluation has been carried out well judging by the average value of 13.33.
\end{abstract}

Keywords: evaluation, finishing building, implementation of $\mathrm{K} 3$. 


\section{PENDAHULUAN}

Sejalan dengan perkembangan sosial, budaya dan ekonomi serta informasi, maka kebutuhan air bersih sangatlah penting bagi masyarakat khususnya masyarakat di wilayah kota. Kebutuhan air sampai dengan saat ini menjadi kebutuhan pokok yang vital, baik untuk irigasi dan industri lainnya. Di Proyek Pembangunan Penyediaan Air Baku Semarang Barat yang terletak di Jln. Untung Suropati, Kedungpane, Mijen Kota Semarang dengan kontraktor PT. Wijaya Karya (Persero)Tbk. Akan mensuplai kebutuhan air bersih bagi sekitar 420 ribu jiwa, atau sekitar 30\% warga Semarang melalui 70 ribu sambungan pipa ke rumah warga di tiga kecamatan yaitu kecamatan Tugu, Ngaliyan, Semarang Barat. Pembangunan Sistem Penyediaan Air Minum (SPAM) sudah di tunggu-tunggu masyarakat. Dengan pembangunan Intake 1.050 liter/detik, pemasangan pipa transmisi air baku sepanjang 2,2 $\mathrm{km}$, pembangunan instalasi pengolahan air berkapasits 1.000 liter/detik, pipa transmisi pengolahan air mengunakan 4 resevoir. Proyek Pembangunan Penyediaan Air Baku Semarang Barat diharapkan dapat membantu kemudahan program sanitasi dan air bersih sebagai bagian mengurangi kemiskinan dan memberikan kesejahteraan untuk masyarakat. Dan di Proyek Pembangunan Penyediaan Air Baku Semarang Barat ini tidak lepas dari masalah Keselamatan dan Kesehatan Kerja (K3) baik di proyek kosntruksi, lapangan kerja maupun di dunia industri. Pentingnya penelitian tentang penerapan $\mathrm{K} 3$ didalam pekerja diproyek konstruksi sebagai upaya pencegahan berbagai potensi bahaya. Penerpan K3 diperusahaan perlu dilakukan karena perusahaan bertanggung jawab penuh kepada pekerjanya karena jika terjadi kecelakaan kerja yang dirugikan kedua belah pihak yaitu pekerja dan perusahaan. Sehigga diharapkan nantinya dapat dijadikan pengetahuan bagi pekerja dalam menjaga K3 apabila mereka bekerja pada sebuah perusahaan.

\section{LANDASAN TEORI}

\subsection{Evaluasi}

Evaluasi secara harfiah berasal dari bahasa inggris dengan kata evaluation yang berarti penilaian atau penaksiran (John dan Hasan, 2003). Evaluasi menurut Poerwadharminta (2014) berarti penilaian atau menilai. Menurut Suharsimi dan Cepi (2010: 2) evaluasi adalah kegiatan untuk mengumpulkan informasi untuk selanjutnya informasi tersebut digunakan untuk menentukan alternatif yang tepat dalam mengambil sebuah keputusan. Dan diperlukan evaluasi berkala sehingga dapat mengambil keputusan dengan baik. Jadi dapat disimpulkan evaluasi adalah kegiatan untuk mengkumpulkan data informasi, dimana data tersebut nantinya untuk menentukan alternatif yang tepat suatu penilaian untuk menentukan hasil yang diambil suatu kepusutan yang tepat.

\subsection{Penerapan Keselamatan dan Kesehatan Kerja (K3)}

Pada dasarnya penerapan Keselamatan dan Kesehatan Kerja (K3) bukan hanya sebagai kewajiban, akan tetapi sudah menjadi kebutuhan 
untuk setiap bentuk kegiatan pekerjaan. Oleh karena itu pentingnya undang-undang K3 untuk menjamin perlindungan bagi pekerja. Dengan begitu upaya penerapan K3 adalah untuk menjamin kebutuhan dan kesehatan para pekerja baik jasmani dan rohani serta untuk mencegah kemungkinan terjadinya kecelakaan kerja. Prosedur yang berkaitan dengan keamanan, keselamatan, dan kesehatan kerja adalah SOP atau di sebut dengan Standar Operasional Prosedur. SOP adalah suatu standar operasi dari unit manajemen untuk memberikan kenyamanan dan keamanan bagi setiap pekerja secara langsung maupun tidak langsung dan dapat meningkatkan produktifitas pekerja. Setiap pekerja wajib memahami dan melaksanakan SOP K3 yang sudah ditetapkan. Tujuan dari SOP K3 antara lain yaitu:

a). Melindungi pekerja dari bahaya kecelakaan kerja dilapangan maupu gangguan kesehatan yang di alami oleh pekerja saat diilapangan.

b). Meningkatkan K3 didalam unit manajemen baik secara jasmani maupun rohani.

c). Menempatkan tenaga kerja pada suatu lingkungan yang sesuai dengan kondisi dilapangan.

d). Mencegah timbulnya gangguan kesehatan yang disebabkan oleh kondisi kerja.

Ada beberapa alasan sebuah kecelakaan kerja bisa terjadi. Didalam melaksanakan pekerjaan tentunya potensi bahaya akan selalu ada dengan melaksanakan proses pekerjaan sesuai dengan SOP K3 yang telah ditetapkan dengan baik kemungkinan bahaya kecelakaan kerja bisa di kurangi.

\subsection{Dasar Hukum Keselamatan dan}

\section{Kesehatan Kerja}

Keselamatan dan Kesehatan Kerja (K3) salah satu ketentuan perundang-undangan yang diterapkan didalam K3 dan memiliki landasan hukum yang wajib dipatuhi untuk melindungi hak pekerja akibat kecelakaan kerja. Menurut (Soehatman, 2010, hal. 11-12) di indonesia juga memiliki dasar hukum K3, berikut diantaranya adalah:

a). Undang-undang No. 1 tahun 1970 tentang keselamatan kerja di berlakukan pada tanggal 12 januari 1970. Dalam undang-undang ini memuat tentang keselamatan kerja mengenai kewajiban dan hak setiap tenaga kerja.

\subsection{Finishing Bangunan}

Pekerjaan finishing merupakan pekerjaan akhir dari sebuah kegiatan pembangunan baik itu gedung, jembatan, jalan, bendung, maupun kegiatan lainnya. Pekerjaan finishing adalah pekerjaan yang berkaitan dengan penutupan dan lapisan sehingga upaya untuk menghaluskan dan merapikan sebuah bangunan menjadi lebih indah. Pekerjaan ini dilaksanakan setelah semua struktur bangunan selesai dilakukan. Berikut ini fungsi dari pekerjaan finishing bangunan:

a). Untuk menambah keawetan bangunan tersebut.

b). Untuk melapisi setiap bagian-bagian yang harus ditampilkan dengan bahan lain.

c). Untuk menambah estetika pada sebuah bangunan agar terlihat lebih indah dan menarik. d). Untuk merapikan setiap bagian kostruksi bangunan agar terlihat sempurna sesuai standar 
yang berlaku.

\section{METODE PENELITIAN}

Penelitian ini menggunakan metode evaluasi Countenance Stake. Dalam penelitian ini metode Countenance Stake terdapat 3 tahapan yang dilakukan antaranya adalah antecedents (input), transcription (proses), dan output (hasil).

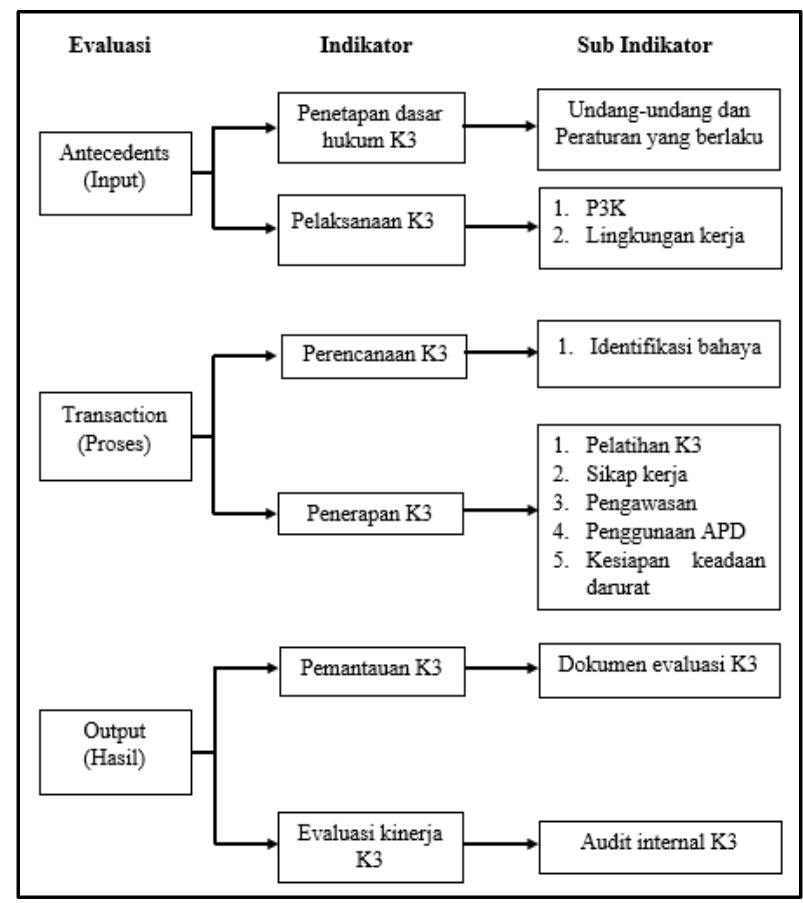

Gambar 1. Model Evaluasi Countenance Stake

Nantinya yang menjadi sampel yaitu semua pekerja di Proyek Pembangunan Penyediaan Air Baku Semarang Barat yang berjumlah 30 pekerja dan 3 Safety Officer maka pada tahap ini pekerja berjumlah 33 orang diambil sebagai sampel dalam penerapan K3 dan pemahaman K3. Menggunakan alat uji sebagai berikut:

\subsection{Uji Validitas Intrumen}

Uji validitas atau uji stastistik ini penting dilakukan agar intrumen yang digunakan untuk mengukur sah atau valid tidaknya suatu kuesioner. Teknik pengujian validitas instrumen konstrak menggunakan rumus korelasi product moment.

\subsection{Uji Reliabilitas Intrumen}

Pengujian reliabilitas intrumen dilakukan untuk mengukur suatu kestabilan dan konsistensi responden dalam menjawab hal yang berkaitan denga pertanyaan suatu variabel disusun dalam bentuk kuesioner. Didalam penelitian ini menggunakan rumus Cronbach Alpha untuk menguji reliabilitas instrumen skala likert.

\subsection{Kecukupan Uji Data}

Uji kecukupan data untuk mendapatkan hasil yang didapatkan apakah sudah cukup untuk mewakili keseluruhan populasi. Pengujian kecukupan data dilakukan untuk mengetahui laporan yang dikumpulkan sudah cukup dan obyektif.

\subsection{Teknik Analisis Data}

Penelitian ini menggunakan statistik deskriptif pada masing-masing variabel yang di analisis dengan perhitungan gejala pusat (Central Tendency) dengan skala asertivitas model skala likert seperti banyaknya subjek (n), skor minimum (Xmax), skor maksimum (Xmin), Mean (m), deviasi standar (s), varians $\left(\mathrm{s}^{2}\right)$. Untuk menentukan kategori skor menggunakan SPSS.

\section{PEMBAHASAN}

Proyek Pembangunan Penyediaan Air Baku Semarang Barat yang beralamat dijalan Untung Suropati, Kedungpane, Mijen, Kota Semarang dengan kontraktor PT. Wijaya Karya (Persero)Tbk merupakan proyek konstruksi 
yang mengerjakan pekerjaan dibagian kolam retensi atau pengolahan air siap pakai. Proyek Kerja sama Pemerintah Badan Usaha (KPBU) dan Instalasi Pengolahan Air Minum (IPAM) Semarang Barat ini diharapkan dapat membantu kemudahan program sanitasi dan air bersih sebagai bagian mengurangi kemiskinan dan memberikan kesejahteraan untuk masyarakat. Hasil yang didapatkan menggunakan metode Countenance Stake dengan tahapan antecedents (input), transcription (proses), dan output (hasil). Dijelaskan sebagai berikut:

\subsection{Data Antecedent (Masukan)}

a. Tahapan Penetapan Dasar Hukum K3 dan Pelaksanaa K3

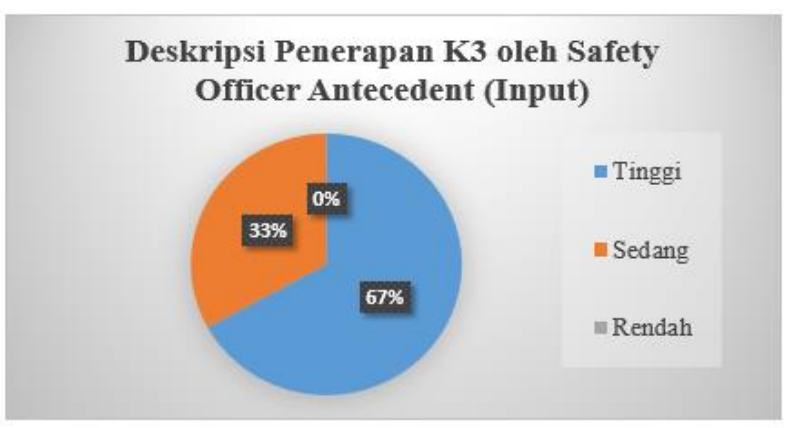

Gambar 2. Indikator Penetapan Dasar Hukum K3 dan Pelaksanaan K3

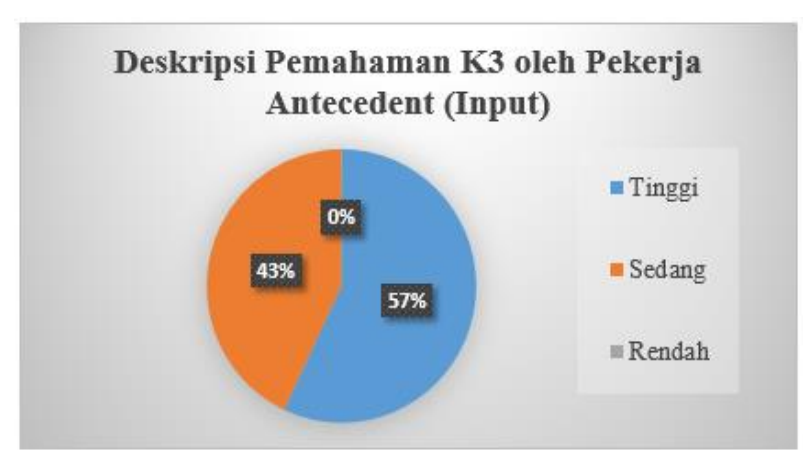

Gambar 3. Indikator Penetapan Dasar Hukum K3 dan Pelaksanaan K3

Hasil perhitungan data dengan rincian skor tertinggi (ST), skor terendah (SR), rata-rata
(Mean), Modus (Mo), Median (Me), dan standar deviasi (SDi). Rincian sebagai berikut:

Tabel 1. Perhitungan Skor Indikator Penetapan Dasar Hukum K3 dan Pelaksanaan K3

\begin{tabular}{|c|c|c|c|c|c|c|}
\hline Responden & ST & SR & Mean & Me & Mo & SDi \\
\hline Safety Officer & 36.00 & 9.00 & 28.33 & 32.00 & 32.00 & 4.50 \\
\hline Pekerja & 36.00 & 9.00 & 27.27 & 27.00 & 26.00 & 4.50 \\
\hline
\end{tabular}

Jadi tahapan penetapan dasar hukum K3 dan pelaksanaan K3 berdasarkan data kuesioner yang didapatkan, untuk responden safety officer mengkategorikan tahapan penetapan dasar hukum K3 dan pelaksanaan K3 dikatakan tinggi ditunjukan dengan nilai rata-rata 28.33 untuk penerapan K3 dilapangan, dan untuk responden pekerja mengkategorikan tahapan penetapan dasar hukum K3 dan pelaksanaan K3 dikatakan tinggi ditunjukan dengan nilai rata-rata 27.27 untuk pemahaman K3 diproyek kostruksi. Untuk penerapan K3 oleh safety officer mendapatkan nilai presentase $67 \%$ yang artinya tinggi dan untuk pemahaman $\mathrm{K} 3$ oleh pekerja mendapatkan nilai presentase $57 \%$ yang artinya tinggi.

\section{1). Tahapan penetapan dasar hukum $K 3$}

Penetapan dasar hukum K3 dari data kuesioner antara responden safety officer dan pekerja data yang diperoleh mengenai undang-undang Nomor 1 tahun 1970 tentang K3 dan SKB MENAKER \& PU Nomor 174/104/86 tentang K3 Konstruksi sudah dilaksanakan dengan baik sesuai objek yang di teliti mengenai pedoman K3 dan SOP K3 dapat dipahami oleh pekerja dengan kebijakan-kebijakan yang dilaksanakan sesuai visi dan misi dari perusahaan.

2). Tahapan pelaksanaan $\mathrm{K} 3$ 
Pelaksanaan K3 dari data kuesioner antara responden safety officer dan pekerja data yang diperoleh mengenai sub indikator P3K dan lingkungan kerja sudah dilaksanakan dengan baik dan dapat dipahami oleh pekerja. Berdasarkan hasil observasi dan dokumentasi mengenai pelaksanaan K3 sudah terlaksana dengan baik dan sudah diterapkan diproyek konstruksi.

\subsection{Data Transaction (Proses)}

a. Tahapan Perencanaan K3 dan Penerapan K3

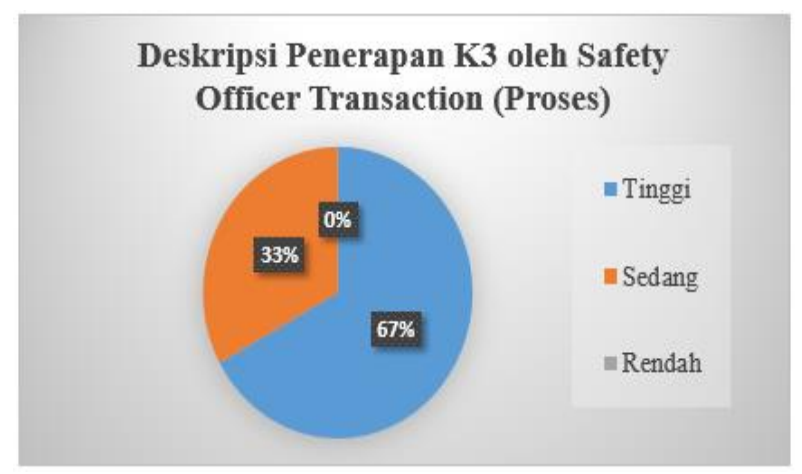

Gambar 4. Indikator Perencanaan K3 dan Penerapan K3

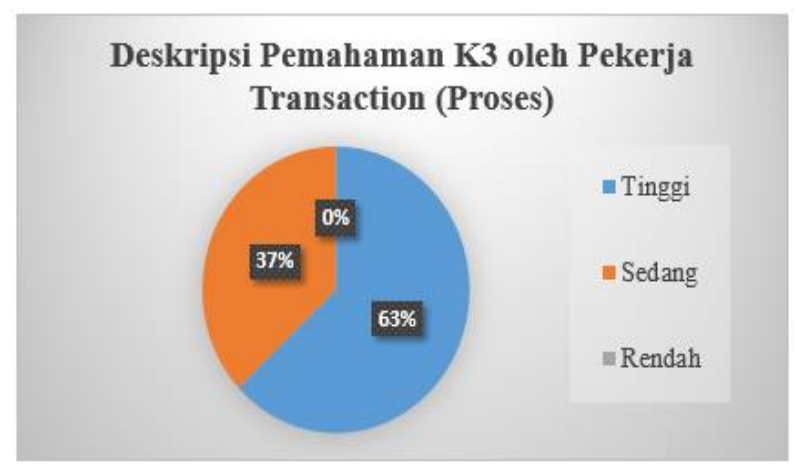

Gambar 5. Indikator Perencanaan K3 dan Penerapan K3

Hasil perhitungan data dengan rincian skor tertinggi (ST), skor terendah (SR), rata-rata (Mean), Modus (Mo), Median (Me), dan standar deviasi (SDi). Rincian sebagai berikut:
Tabel 2. Perhitungan Skor Indikator Perencanaan K3 dan Penerapan K3

\begin{tabular}{|c|c|c|c|c|c|c|}
\hline Responden & ST & SR & Mean & Me & Mo & SDi \\
\hline Safety Officer & 32.00 & 8.00 & 24.67 & 28.00 & 28.00 & 4.00 \\
\hline Pekerja & 36.00 & 9.00 & 28.17 & $25.00 \mathrm{a}$ & 28.00 & 4.50 \\
\hline
\end{tabular}

Tahapan perencanaan K3 dan penerapan K3 berdasarkan data kuesioner yang didapatkan, untuk responden safety officer mengkategorikan tahapan perencanaan $\mathrm{K} 3$ dan penerapan $\mathrm{K} 3$ tinggi ditunjukan dengan nilai rata-rata 24.67 untuk penerapan K3 dilapangan, dan untuk responden pekerja mengkategorikan tahapan perencanaan $\mathrm{K} 3$ dan penerapan $\mathrm{K} 3$ tinggi ditunjukan dengan nilai rata-rata 28.17 untuk pemahaman K3 diproyek kostruksi. Untuk penerapan K3 oleh safety officer mendapatkan nilai presentase $67 \%$ yang artinya tinggi dan untuk pemahaman K3 oleh pekerja mendapatkan nilai presentase $63 \%$ yang artinya tinggi.

\section{1). Tahapan perencanaan $\mathrm{K} 3$}

Perencanaan K3 dari data kuesioner antara responden safety officer dan pekerja data yang diperoleh mengenai sub indikator identifikasi bahaya sudah dilaksanakan dengan baik dan dapat dipahami oleh pekerja. Berdasarkan hasil observasi dan dokumentasi mengenai perencanaan K3 sudah terlaksana dengan baik dan sudah diterapkan diproyek konstruksi.

2). Tahapan penerapan $\mathrm{K} 3$

Penerapan K3 dari data kuesioner antara responden safety officer dan pekerja data yang diperoleh mengenai sub indikator pelatihan $\mathrm{K} 3$, sikap kerja, pengawasan, penggunaan APD, kesiapan keadaan darurat sudah dilaksanakan 
dengan baik dan dapat dipahami oleh pekerja. Berdasarkan hasil observasi dan dokumentasi mengenai penerapan K3 sudah terlaksana dengan baik dan sudah diterapkan diproyek konstruksi.

\subsection{Data Output (Hasil)}

a. Tahapan Pemantauan K3 dan Evaluasi

\section{Kinerja K3}

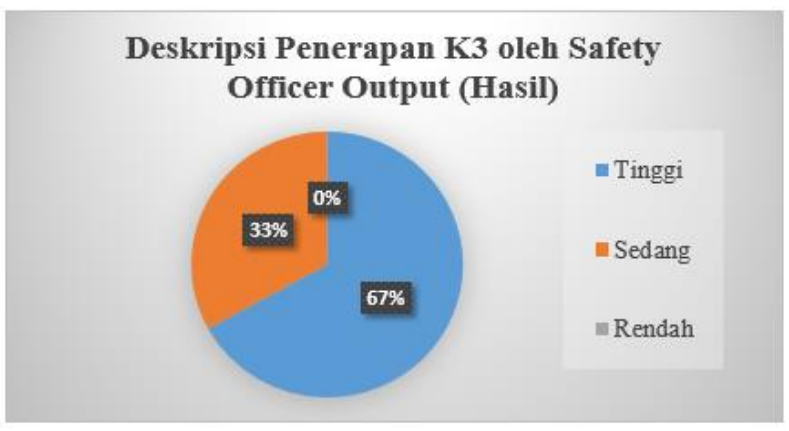

Gambar 7. Indikator Pemantauan K3 dan Evaluasi Kinerja K3

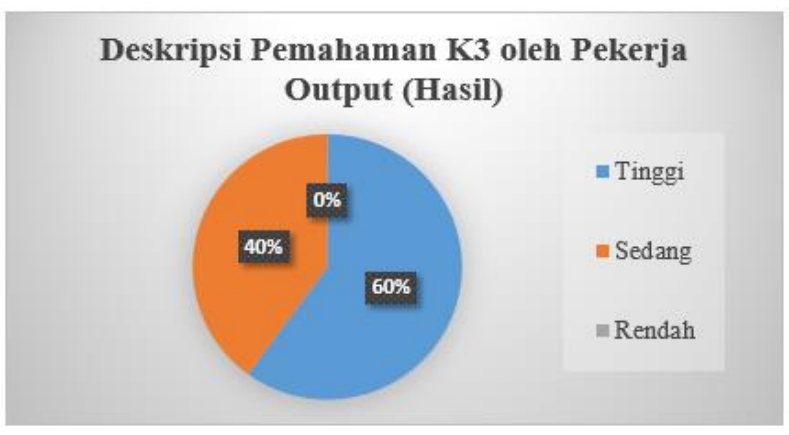

Gambar 8. Indikator Pemantauan K3 dan Evaluasi Kinerja K3

Hasil perhitungan data dengan rincian skor tertinggi (ST), skor terendah (SR), rata-rata (Mean), Modus (Mo), Median (Me), dan standar deviasi (SDi). Rincian sebagai berikut:

Tabel 3. Perhitungan Skor Indikator Pemantauan K3 dan Evaluasi Kinerja K3

\begin{tabular}{|c|c|c|c|c|c|c|}
\hline Responden & ST & SR & Mean & Me & Mo & SDi \\
\hline Safety Officer & 16.00 & 4.00 & 13.33 & 15.00 & 15.00 & 2.00 \\
\hline Pekerja & 12.00 & 3.00 & 8.83 & 9.00 & 9.00 & 1.50 \\
\hline
\end{tabular}

Tahapan Pemantauan K3 dan Evaluasi Kinerja K3 berdasarkan data kuesioner yang didapatkan, untuk responden safety officer mengkategorikan tahapan Pemantauan K3 dan Evaluasi Kinerja K3 tinggi ditunjukan dengan nilai rata-rata 13.33 untuk penerapan K3 dilapangan, dan untuk responden pekerja mengkategorikan tahapan Pemantauan K3 dan Evaluasi Kinerja K3 sedang ditunjukan dengan nilai rata-rata 8.83 untuk pemahaman K3 diproyek kostruksi ini menunjukan bahwa pekerja belum sepenuhnya mengetahui tentang $\mathrm{K} 3$ yaitu mengenai variabel output dengan indikator pemantauan $\mathrm{K} 3$ dan evaluasi kinerja $\mathrm{K} 3$ untuk sub indikator dokumen evaluasi K3 dan audit internal K3 dengan objek yang diteliti mengenai pelaporan dan pencatatan kecelakaan kerja, pemeliharaan sarana dan prasarana, pemantauan kesehatan dan evaluasi K3. Untuk penerapan K3 oleh safety officer mendapatkan nilai presentase $67 \%$ yang artinya tinggi dan untuk pemahaman K3 oleh pekerja mendapatkan nilai presentase $60 \%$ yang artinya tinggi.

1). Tahapan Pemantauan K3

Pemantauan K3 dari data kuesioner antara responden safety officer dan pekerja data yang diperoleh mengenai sub indikator dokumen evaluasi K3 sudah dilaksanakan dengan baik dan dapat dipahami oleh pekerja. Berdasarkan hasil observasi dan dokumentasi mengenai Pemantauan K3 sudah terlaksana dengan baik dan sudah diterapkan diproyek konstruksi.

2). Tahapan Evaluasi Kinerja K3

Evaluasi kinerja K3 dari data kuesioner antara responden safety officer dan pekerja data yang 
diperoleh mengenai sub indikator audit internal K3 sudah dilaksanakan dengan baik dan dapat dipahami oleh pekerja. Berdasarkan hasil observasi dan dokumentasi mengenai Evaluasi kinerja K3 sudah terlaksana dengan baik dan sudah diterapkan diproyek konstruksi.

\section{KESIMPULAN}

Di Proyek Pembangunan Penyediaan Air Baku Semarang Barat berdasarkan hasil penelitian dari pembahasan yang telah disajikan, maka dapat di ambil kesimpulan sebagai berikut:

1. Antecedent (input) dari penerapan K3 oleh safety officer sudah terlaksana dengan baik dan mendapatkan kategori tinggi dilihat dari nilai rata-rata 28.33 yang sudah di terapkan dilapangan dan ditinjau dari penetapan dasar hukum K3 dan pelaksanaan K3 yang sudah berjalan dengan baik.

Antecedent (input) dari pemahaman K3 oleh pekerja sudah terlaksana dengan baik dan mendapatkan kategori tinggi dilihat dari nilai rata-rata 27.27 untuk pemahaman diproyek konstruksi dan ditinjau dari penetapan dasar hukum K3 dan pelaksanaan K3 yang sudah berjalan dengan baik.

2. Transaction (proses) dari penerapan K3 oleh safety officer sudah terlaksana dengan baik dan mendapatkan kategori tinggi dilihat dari nilai rata-rata 24.67 yang sudah di terapkan dilapangan dan ditinjau dari perencanaan K3 dan penerapan K3 yang sudah berjalan dengan baik.

Transaction (Proses) dari pemahaman K3 oleh pekerja sudah terlaksana dengan baik dan mendapatkan kategori tinggi dilihat dari nilai rata-rata 28.17 untuk pemahaman diproyek konstruksi dan ditinjau dari perencanaan K3 dan penerapan K3 yang sudah berjalan dengan baik.

3. Output (Hasil) dari penerapan $\mathrm{K} 3$ oleh safety officer sudah terlaksana dengan baik dan mendapatkan kategori tinggi dilihat dari nilai rata-rata 13.33 yang sudah di terapkan dilapangan dan ditinjau dari pemantauan K3 dan evaluasi kinerja K3 yang sudah berjalan dengan baik.

Output (Hasil) dari pemahaman K3 oleh pekerja belum terlaksana dengan baik dan mendapatkan kategori sedang dilihat dari nilai rata-rata 8.83 untuk pemahaman diproyek konstruksi dan ditinjau dari pemantauan $\mathrm{K} 3$ dan evaluasi kinerja K3 yang belum berjalan dengan baik, ini menunjukan bahwa pekerja belum sepenuhnya mengetahui tentang K3 yaitu mengenai variabel output dengan indikator pemantauan $\mathrm{K} 3$ dan evaluasi kinerja K3 untuk sub indikator dokumen evaluasi K3 dan audit internal K3 dengan objek yang diteliti mengenai pelaporan dan pencatatan kecelakaan kerja, pemeliharaan sarana dan prasarana, pemantauan kesehatan dan evaluasi K3.

\section{UCAPAN TERIMA KASIH}

Puji syukur Alhamdulilah kami panjatkan kehadirat Allah Tuhan Yang Maha Esa, atas limpahan rahmat dan hidayahnya sehingga kami dapat menyelesaikan penelitian ini. Terima kasih kami haturkan kepada Universitas PGRI Semarang. 


\section{DAFTAR PUSTAKA}

Arikunto, Suharsimi \& Safrudin, Cepi. Jabar. (2010). Evaluasi Program Pendidikan, Pedoman Teoritis Praktis Bagi Mahasiswa dan Praktisi Pendidikan. Jakarta: Bumi Aksara.

Echols, John dan Shadily, Hasan. (2003). An English-Indonesia Dictoinary. Jakarta: Gramedia.

Poerwadharminta, H.S.S. (2014). Kamus Umum Bahasa Indonesia. Jakarta: PT Gramedia.

Ramli, Soehatman. (2010). Sistem Manajemen Keselamatan dan Kesehatan Kerja OHSAS 18001. Jakarta: Dian Rakyat.

Undang Undang No. 1 Tahun 1970 tentang Keselamatan Kerja.

Undang Undang Nomor 1 tahun 1970 tentang K3 dan SKB MENAKER \& PU Nomor 174/104/86 tentang K3 Konstruksi. 